\title{
Crescimento micelial radial e esporulação de isolados de Corynespora cassiicola
}

\author{
Flávia Elis de Mello ${ }^{1}$; Helen Prudente da Silva²; Gabriela Gomes Celestino \\ Ivani de Oliveira Negrão Lopes ${ }^{3}$; Maria Isabel Balbi-Peña ${ }^{1}$; Cláudia Vieira Godoy ${ }^{3}$
}

${ }^{1}$ Universidade Estadual de Londrina, Caixa Postal 6001, CEP 86051-970, Londrina, PR, Brasil. ²Bolsista de iniciação científica do Conselho Nacional de Desenvolvimento Científico e Tecnológico. ${ }^{3}$ Embrapa Soja, Caixa Postal 231, CEP 86001-970, Londrina, PR, Brasil.

Autor para correspondência: Flávia Elis de Mello (flaviamello_89@hotmail.com)

Data de chegada: 27/03/2017. Aceito para publicação em: 15/08/2017.

$10.1590 / 0100-5405 / 177612$

\section{RESUMO}

Mello, F.E.; Silva, H.P.; Gomes, G. C.; Lopes, I.O.N.; Balbi-Peña, M.I.; Godoy, C.V. Crescimento micelial radial e esporulação de isolados de Corynespora cassiicola. Summa Phytopathologica, v.44, n.4, p.374-379, 2018.

O fungo Corynespora cassiicola, agente causal da mancha-alvo na soja, apresenta baixa esporulação em meios de cultura artificiais, o que dificulta a produção de esporos em condições de laboratório. O objetivo deste estudo foi avaliar a esporulação e o crescimento micelial radial de 21 isolados de C. cassiicola, obtidos de folhas de soja coletadas nas principais regiões produtoras do Brasil e submetidos a diferentes regimes de iluminação e estresse. Os isolados foram submetidos a três regimes de iluminação: luz contínua, 12 h/12 h de luz-escuro e escuro contínuo e duas condições de estresse mecânico: raspagem superficial da colônia ou ausência de estresse. A produção de esporos dos isolados foi quantificada utilizando um hemacitômetro, enquanto o crescimento micelial radial foi realizado pela média de dois diâmetros perpendiculares da colônia. A esporulação e o crescimento micelial radial sob diferentes regimes de iluminação e estresse, apresentaram comportamentos específicos para cada isolado. Não foi observada correlação significativa entre o crescimento micelial e a produção de esporos.

Palavras-chave: conídios, esporos, mancha-alvo, produção de inóculo, soja.

\section{ABSTRACT}

Mello, F.E.; Silva, H.P.; Gomes, G.C.; Lopes, I.O.N.; Balbi-Peña, M.I.; Godoy, C.V. Radial mycelial growth and sporulation of Corynespora cassiicola isolates. Summa Phytopathologica, v.44, n.4, p.374-379, 2018.

The fungus Corynespora cassiicola, the causal agent of soybean target spot, presents low sporulation in artificial culture media, which makes difficult the production of spores under laboratory conditions. The objective of this study was to evaluate the sporulation and the mycelium radial growth of 21 C. cassiicola isolates obtained from soybean leaves collected from the main soybean growing regions in Brazil and subjected to different light and stress regimes. The isolates were subjected to three light regimes: continuous light, 12 $\mathrm{h} / 12 \mathrm{~h}$ light-dark and continuous dark, and two mechanical stress conditions: superficial scraping of the colony or absence of stress. The spore production of isolates was quantified by using a hemacytometer, while the radial mycelium growth was determined based on the average of two perpendicular diameters of the colony. Sporulation and mycelium radial growth under different light and stress regimes presented specific behaviors for each isolate. There was no significant correlation between mycelial growth and spore production.

Keywords: conidia, spores, target spot, inoculum production, soybean.

No Brasil, a soja [Glycine max (L.) Merrill] na safra de 2016/17 atingiu uma área de cultivo de aproximadamente 33,8 milhões de hectares, com uma produtividade média nacional de $3.176 \mathrm{~kg} \mathrm{ha}^{-1}$ (4). Com a expansão da área semeada, constata-se um aumento na incidência de doenças na cultura, entre elas a mancha-alvo, causada pelo fungo Corynespora cassiicola (Berk. \& M.A. Curtis) C.T. Wei. Este fungo é cosmopolita, inespecífico e muito agressivo. Já foi relatado causando doença em mais de 350 espécies de plantas em mais de 80 países $(2 ; 7)$.

O primeiro relato na cultura da soja no Brasil ocorreu no ano de 1976 (2) e, desde então, tem-se observado o aumento da incidência dessa doença, ocorrendo atualmente em todas as regiões de cultivo de soja (8). O fungo infecta folhas, pecíolos, vagens, sementes, caule, hipocótilo e raízes (9). As estratégias de manejo envolvem o uso de cultivares resistentes, o tratamento de sementes, a rotação/sucessão de culturas e o controle químico (1). Em razão da baixa eficiência dos fungicidas e da suscetibilidade de algumas cultivares ao patógeno, a doença pode provocar reduções de produtividade de até $35 \%$ (8).
A seleção de cultivares resistentes e o monitoramento da resistência do fungo aos fungicidas exigem a produção de conídios para inoculação e realização de bioensaios. A baixa produção de esporos de C. cassiicola torna laboriosa a produção de inóculo em laboratório. Assim, faz-se necessário otimizar os fatores que influem no crescimento micelial e na esporulação do fungo, em condições artificiais, para contribuir com os estudos desse patógeno.

Trione \& Leach (12) relataram que a iluminação contínua em diversos fungos ativa enzimas-chave que induzem a produção de esporos. Beckman \& Paine (3) afirmam que a quantidade e a qualidade de luz necessárias para induzir a produção das estruturas reprodutivas variam de acordo com a espécie de fungo. Onesirosan et al. (10) avaliaram 28 isolados de $C$. cassiicola e observaram que a luz contínua aumentou a esporulação em até 50 vezes em comparação com o tratamento sem iluminação. Estes autores observaram que a produção de esporos de $C$. cassiicola aumentou quando os isolados foram submetidos a injúria superficial do micélio, após três dias de 
crescimento, seguido por exposição luminosa contínua. Além disso, foi observado que a injúria física sem a exposição da luz ou o tratamento luminoso sem o estresse inicial, não estimulava a esporulação.

Dessa forma, os objetivos deste trabalho foram avaliar o crescimento micelial radial e a esporulação de 21 isolados C. cassiicola, procedentes das principais regiões sojícolas do Brasil, submetidos a diferentes regimes de iluminação e estresse mecânico.

\section{MATERIAL E MÉTODOS}

Folhas de soja com sintomas típicos de mancha-alvo foram coletadas em nove regiões sojícolas do Brasil. O isolamento do fungo foi realizado de forma indireta em meio de cultura batata-dextroseágar (BDA; $4 \mathrm{~g} \mathrm{~L}^{-1}$ extrato de batata, $20 \mathrm{~g} \mathrm{~L}^{-1}$ dextrose, $15 \mathrm{~g} \mathrm{~L}^{-1}$ ágar, pH 5,6 \pm 0,2), e a identificação da espécie ocorreu pela comparação de características morfológicas das colônias e dos conidióforos e conídios com os descritos na literatura $(6 ; 9)$. Após a purificação, os isolados foram armazenados pelo método Castellani.

Foram obtidos 21 isolados de $C$. cassiicola provenientes dos Estados do Paraná (CMES 1163-Londrina, CMES 2313-Boa Esperança e CMES 2713-Cafelândia), São Paulo (CMES 672 Pirassununga), Mato Grosso do Sul (20152-Maracaju e 20153-Ponta Porã), Mato Grosso (CMES 312-Itiquira, CMES 1469-Sinop, CMES 1599-Querência, CMES 6313-Jaciara, 20151-Deciolândia e 20154-Sinop), Goiás (CMES 1588-Goiânia e CMES 1589-Rio Verde), Tocantins (CMES 1503-Pedro Afonso e CMES 1544-Porto Nacional), Maranhão (CMES 1512-Riachão e CMES 1586-Tasso Fragoso), Pará (CMES 1576-não especificado e CMES 1579-não especificado) e Roraima (CMES 1428-Bonfim).

Os 21 isolados de C. cassiicola preservados em Castellani foram cultivados em meio BDA a $24{ }^{\circ} \mathrm{C} \pm 2{ }^{\circ} \mathrm{C}$. Posteriormente, discos de micélio de $7 \mathrm{~mm}$ de diâmetro provenientes da borda de colônias foram transferidos para o centro das placas de Petri contendo meio BDA e incubados a $24{ }^{\circ} \mathrm{C} \pm 2{ }^{\circ} \mathrm{C}$ sob três regimes de iluminação: luz contínua, $12 \mathrm{~h} / 12 \mathrm{~h}$ de luz-escuro e escuro contínuo durante 12 dias.

Após sete dias de incubação, os isolados foram submetidos a estresse mecânico por meio da raspagem superficial da colônia com o auxílio de lâmina de microscopia previamente esterilizada.

O delineamento experimental foi inteiramente casualizado com quatro repetições, sendo cada repetição constituída por uma placa com um isolado. As placas de cada isolado para cada nível de estresse (sem e com raspagem do micélio) foram distribuídas ao acaso em três câmaras de incubação sob diferentes regimes de iluminação à temperatura de $24^{\circ} \mathrm{C} \pm 2{ }^{\circ} \mathrm{C}$ por 12 dias. As câmaras estavam equipadas com lâmpada branca fria fluorescente $(15 \mathrm{~W})$.

A avaliação de crescimento micelial radial foi determinada pela média de dois diâmetros perpendiculares e pelo cálculo da área de crescimento da colônia. A área foi calculada pela fórmula: $\mathrm{A}=\pi\left(\frac{\mathrm{d}}{2}\right)^{2}$ onde, Aé a variável área, $\pi=3,1415$ e d corresponde ao diâmetro médio de duas medidas diametralmente opostas, 12 dias após a incubação.

Para realizar a contagem dos conídios, adicionou-se $10 \mathrm{~mL}$ de água destilada em cada placa e a colônia fúngica foi levemente raspada. Dessa suspensão, foi retirada uma alíquota de $10 \mu \mathrm{L}$ e a concentração de conídios foi determinada com o auxílio de hemacitômetro. Este procedimento foi repetido quatro vezes para cada placa e a quantidade final de esporos foi definida pela média das contagens em cada replicata.

\section{Análise estatística}

O aninhamento dos fatores isolado, estresse e repetição dentro do fator iluminação impossibilitou a aleatorização de todos os níveis dos fatores em estudo. Esse desenho pode ter sido a causa de: ausência de independência entre os resíduos, não-aditividade dos fatores, não-normalidade na distribuição dos resíduos e heterogeneidade de variâncias dos tratamentos. Além das particularidades do desenho experimental, a intensidade de esporulação dos isolados produziu correlação linear entre médias e variâncias na contagem de esporos. Portanto, para acomodar tais características, as análises de variâncias foram realizadas utilizando-se técnicas de modelos lineares generalizados mistos (GLMMs).

Ambas variáveis aferidas nesse estudo foram analisadas assumindo-se a distribuição gama e a função de ligação logaritmo. Modelos utilizando outras distribuições da família exponencial e suas funções de ligação também foram ajustados, tendo sido o modelo final escolhido com base na estatística de qualidade de ajuste AIC (Akaike Information Criterion) e em gráficos de resíduos. Os modelos 1 e 2 foram os que apresentaram melhor ajuste para o número de esporos (1) e para o crescimento radial micelial (2), de acordo com os critérios adotados:

$$
\begin{aligned}
& \underbrace{C}_{\text {vetor dados }}=\underbrace{\mu+R(L)+L+I(L)+E(L)+I E(L)}_{X \beta}+\underbrace{\varepsilon}_{\text {vetor erros }} \\
& \underbrace{C}_{\text {vetor dados }}=\underbrace{\mu+L+I(L)+E(L)+I E(L)}_{X \beta}+\underbrace{R(L)+I R(L)}_{Z \gamma}+\underbrace{\varepsilon}_{\text {vetor erros }}
\end{aligned}
$$

Em que:

$C=$ número de conídios (1) ou o crescimento radial micelial (2);

$\mu=$ média geral;

$L=$ Efeito de iluminação;

$R(L)=$ Efeito de repetição dentro de iluminação;

$I(L)=$ Efeito de isolado dentro de iluminação;

$E(L)=$ Efeito de estresse dentro de iluminação;

$I E(L)=$ Efeito da interação entre os fatores isolado e estresse dentro de iluminação;

$I R(L)=$ efeito da interação entre isolado e bloco dentro de iluminação;

$X=$ matriz do delineamento dos efeitos fixos;

$Z=$ matriz do delineamento dos efeitos aleatórios;

$\beta=$ vetor de coeficientes correspondentes aos efeitos fixos;

$\gamma=$ vetor de coeficientes correspondentes aos efeitos aleatórios.

No Modelo 2, assumiu-se que $\gamma$ e $\varepsilon$ são variáveis aleatórias independentes, com média zero e matrizes de covariância $G$ e $R$, tendo sido seus parâmetros estimados pelo método pseudo-máximaverossimilhança. A matriz $G$ foi utilizada como estratégia de modificação da estrutura da matriz de covariâncias residuais. Uma consequência dessa alteração foi a obtenção de estimativas dos erros padrões da média dos efeitos fixos condicionadas ao efeito aleatório, que no presente estudo permitiu a comparação de médias com variâncias heterogêneas. As médias foram comparadas pelo teste de Tukey, ao nível de significância 0,05 .

As análises estatísticas foram conduzidas utilizando-se rotinas computacionais próprias, no ambiente SAS/STAT software, Versão 9.4. Copyright (C) 2016 SAS Institute Inc.. O procedimento glimmix foi utilizado para estimar os parâmetros dos modelos, os quais foram armazenadas e posteriormente utilizados no procedimento plm para comparações de médias. 


\section{RESULTADOS E DISCUSSÃO}

Efeito da luz, do isolado e do estresse mecânico no crescimento micelial de Corynespora cassiicola

As maiores variabilidades entre as áreas dos micélios foram associadas ao fator isolado (Figura 1). Além disso, observa-se também que alguns isolados responderam ao estresse e/ou ao regime de iluminação. Esse padrão, juntamente com a significância exata do teste $\mathrm{F}$ da interação $I E(L)$ no Modelo $1(p=0,1365)$, indicam que os de efeitos de tratamentos e de isolados devem ser analisados a partir da interação $I E(L)$.

A Tabela 1 mostra os casos em que o estresse e/ou a condição de iluminação alteraram significativamente o crescimento radial micelial médio. Os resultados das comparações múltiplas de médias entre os isolados estão apresentados dentro de cada condição de iluminação e de estresse (letras minúsculas), enquanto as comparações entre as médias obtidas nas três condições de iluminação estão apresentadas dentro de cada condição de estresse para cada isolado (letras maiúsculas). De modo semelhante, o efeito do estresse está apresentado para cada isolado, em cada condição de iluminação (*).

A condição de iluminação alterou significativamente o crescimento micelial de apenas cinco isolados (Tabela 1), tendo sido quatro deles submetido a estresse (CMES 1428, CMES 1469, CMES 2313 e CMES 2713) e o outro na condição sem estresse (CMES 312). Dentre esses quatro isolados, o crescimento micelial no regime de fotoperíodo de três deles (CMES 1428, CMES 1469, CMES 2313) foi maior ou igual ao obtido nos demais regimes. Por outro lado, o crescimento do isolado CMES 312 foi significativamente inferior sob o regime de fotoperíodo $12 \mathrm{~h} / 12 \mathrm{~h}$, na condição sem estresse.

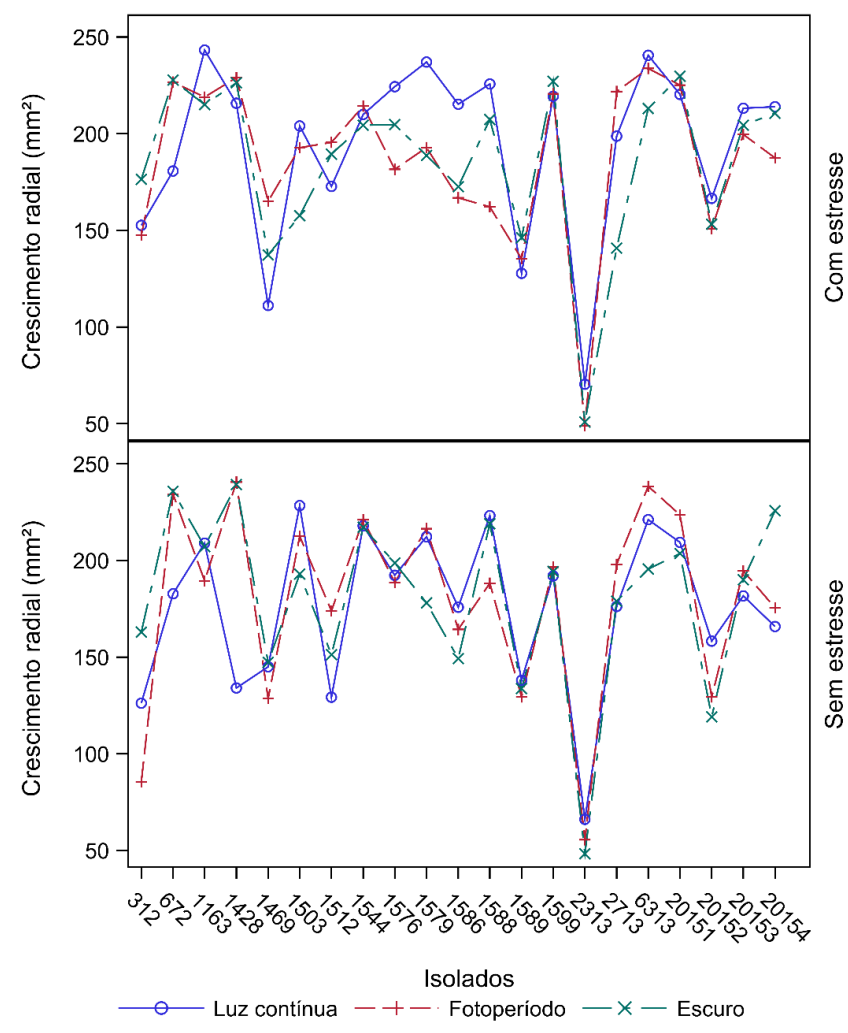

Figura 1. Crescimento micelial de 21 isolados de C. cassiicola submetidos a diferentes regimes de estresse e de iluminação.

Tabela 1. Crescimento micelial $\left(\mathrm{mm}^{2}\right)$ médio de 21 isolados de Corynespora cassiicola da cultura da soja de diferentes regiões do Brasil submetidos a diferentes regimes de iluminação e de estresse mecânico. Médias comparadas pelo teste de Tukey $(p=0,05)$.

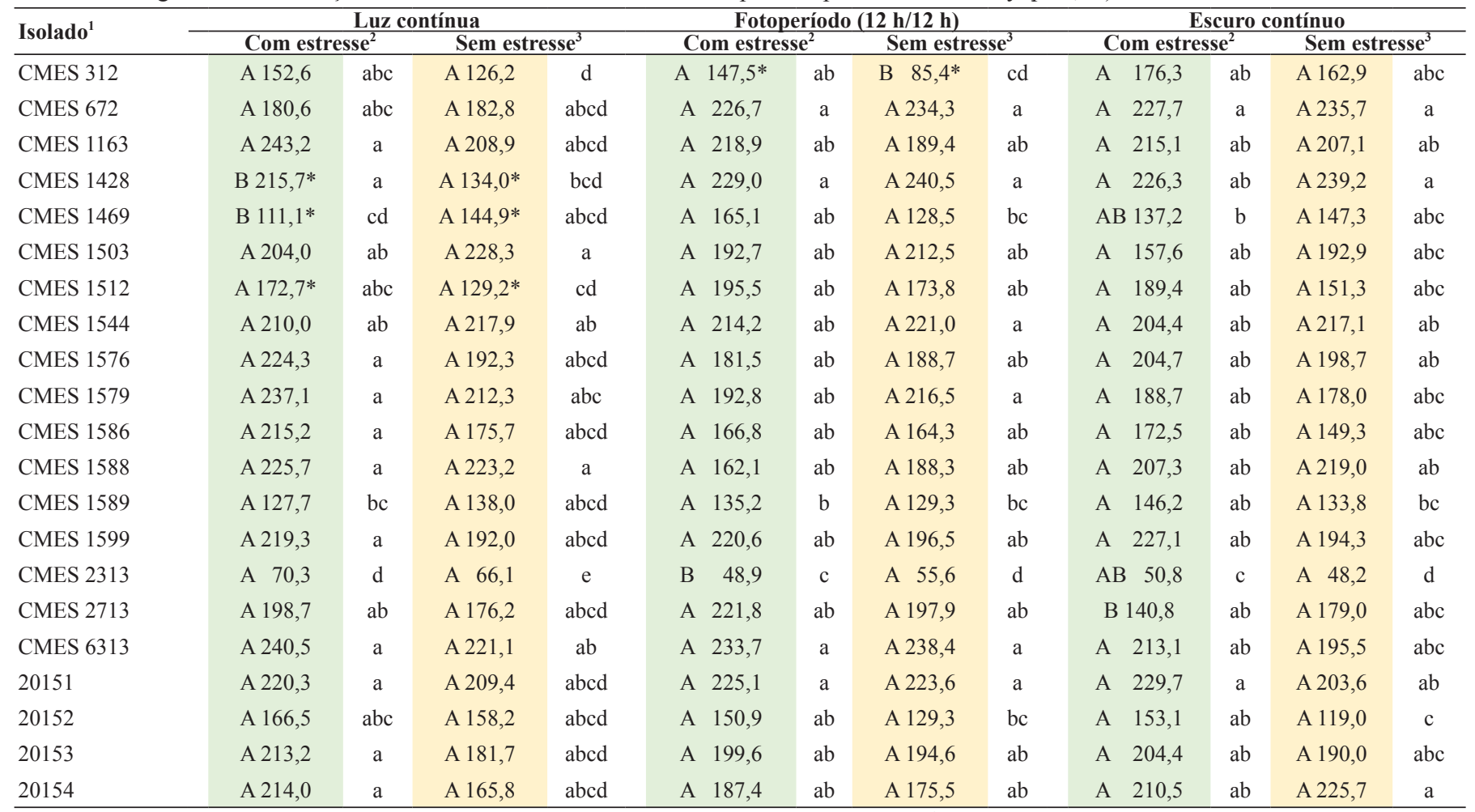

* Isolados que responderam significativamente ao estresse mecânico, em cada condição de iluminação. ${ }^{1}$ Letras minúsculas iguais na coluna indicam isolados que não produziram áreas miceliais significativamente diferentes, em cada condição de estresse e de iluminação. ${ }^{2,3}$ Letras maiúsculas iguais na linha, dentro da condição de estresse mecânico (2) ou sem estresse mecânico (3), indicam os isolados cujas as condições de iluminação não alteraram significativamente o crescimento micelial. 
Almeida e Yamashita (2) observaram que isolados de C. cassiicola provenientes da cultura da soja, apresentaram maior crescimento micelial radial quando submetidos aos tratamentos luz contínua e menor crescimento micelial radial quando submetido ao tratamento escuro contínuo. Neste estudo observou-se, que o crescimento micelial radial é uma característica inerente a cada isolado.Além disso, verificou-se que 16 isolados, dentre os 21, não foram influenciados pelo regime de luz.

Teramoto et al. (11) observaram que o crescimento micelial dos isolados SOMA01 e SOMA02 de C. cassiicola de plantas de soja provenientes do município de Riachão (MA), foram indiferentes ao tratamento luminoso. Neste estudo, verificou-se também que o crescimento micelial radial dos isolados CMES 1512 e CMES 1586, provenientes do mesmo município, não foi significativamente alterado quando submetidos aos diferentes regimes de iluminação. Possivelmente, a adaptação ambiental destes isolados possa ter influenciado para uma menor sensibilidade ao tratamento luminoso.

Efeito de isolados, da luz e do estresse mecânico na produção de conídios de Corynespora cassiicola

Diferente do crescimento micelial, a aplicação dos tratamentos aos isolados de $C$. cassiicola mostrou-se uma eficiente estratégia para aumentar a produção de esporos para a maioria dos isolados. Houve forte interação entre tratamentos e isolados (Figura 2), o que foi confirmado por meio do teste $\mathrm{F}$ da interação $I E(L)$ no Modelo $2(p<0,0001)$. Os isolados mais influenciados pelos tratamentos produziram mais conídios sob os regimes de iluminação contínua e/ ou escuro, independente da condição de estresse (Figura 2), embora a aplicação do estresse também tenha contribuído para aumentar a produção de conídios. Esse resultado está de acordo com Teramoto et al. (11), que verificaram que isolados de C. cassiicola provenientes de

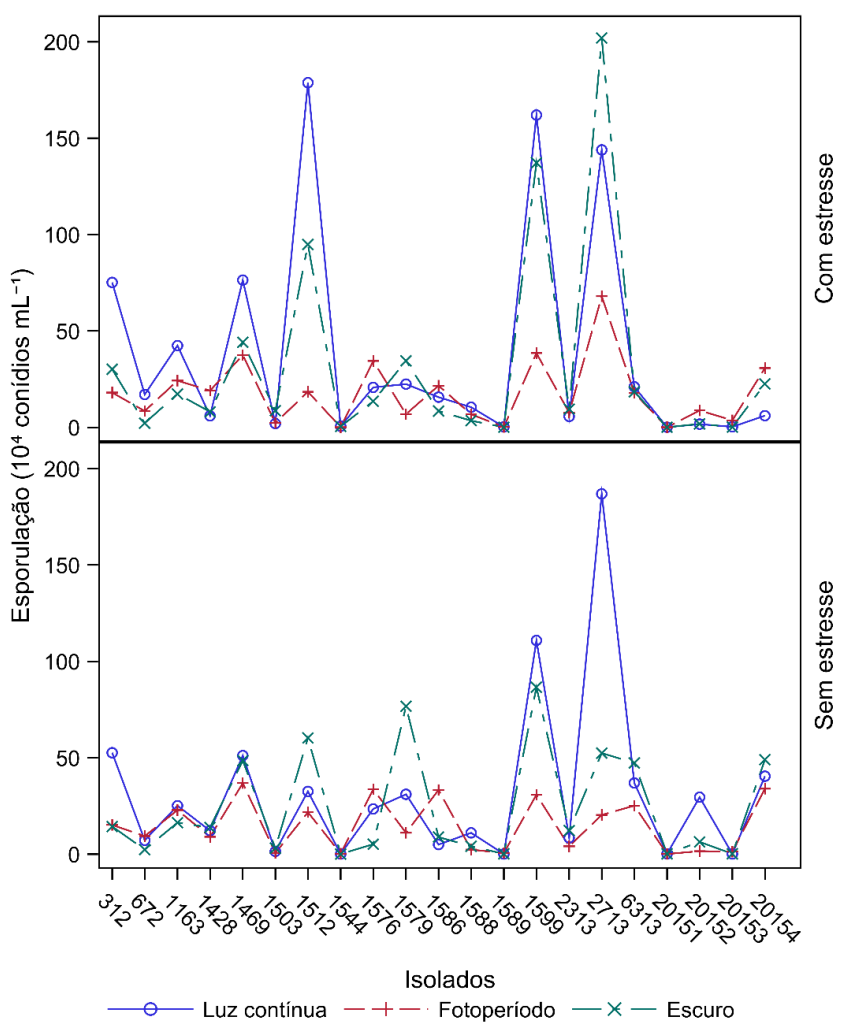

Figura 2. Quantificação de conídios $\left(10^{4}\right.$ conídios $\left.\mathrm{mL}^{-1}\right)$ de 21 isolados de Corynespora cassiicola submetidos a diferentes regimes de iluminação e estresse mecânico.

Tabela 2. Esporulação $\left(10^{4}\right.$ conídios $\left.\mathrm{mL}^{-1}\right)$ média de isolados de Corynespora cassiicola da cultura da soja de diferentes regiões do Brasil submetidos a diferentes condições de luz e estresse mecânico. Médias comparadas pelo teste de Tukey $(p=0,05)$.

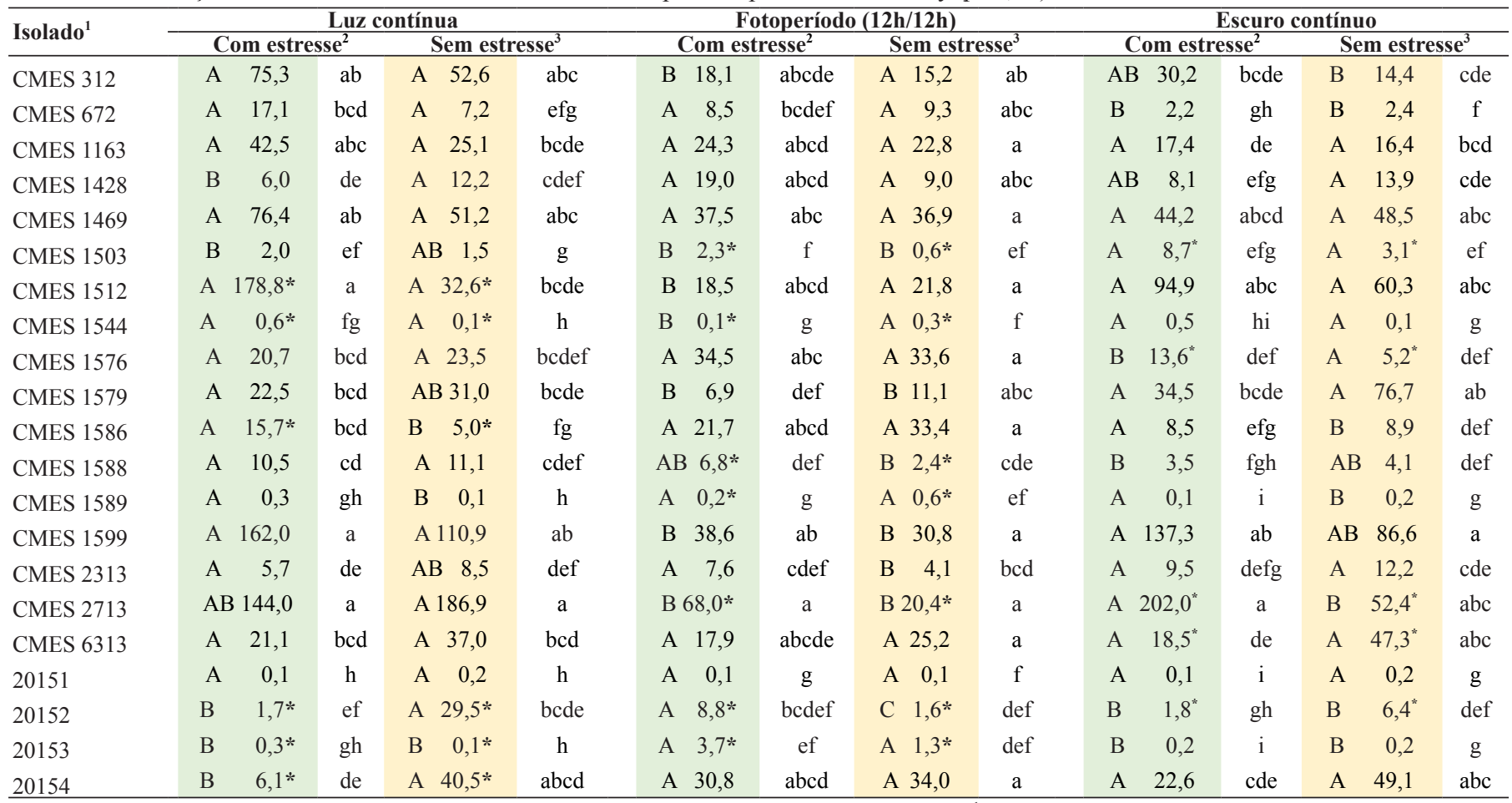

*Isolados que responderam significativamente ao estresse mecânico, em cada condição de iluminação. ${ }^{1}$ Letras minúsculas iguais na coluna indicam isolados que não produziram quantidades significativamente diferentes de conídios, em cada condição de estresse e de iluminação. ${ }^{2,3}$ Letras maiúsculas iguais na linha, dentro da condição de estresse mecânico (2) ou sem estresse mecânico (3), indicam os isolados cujas as condições de iluminação não alteraram significativamente a quantidade de conídios. 


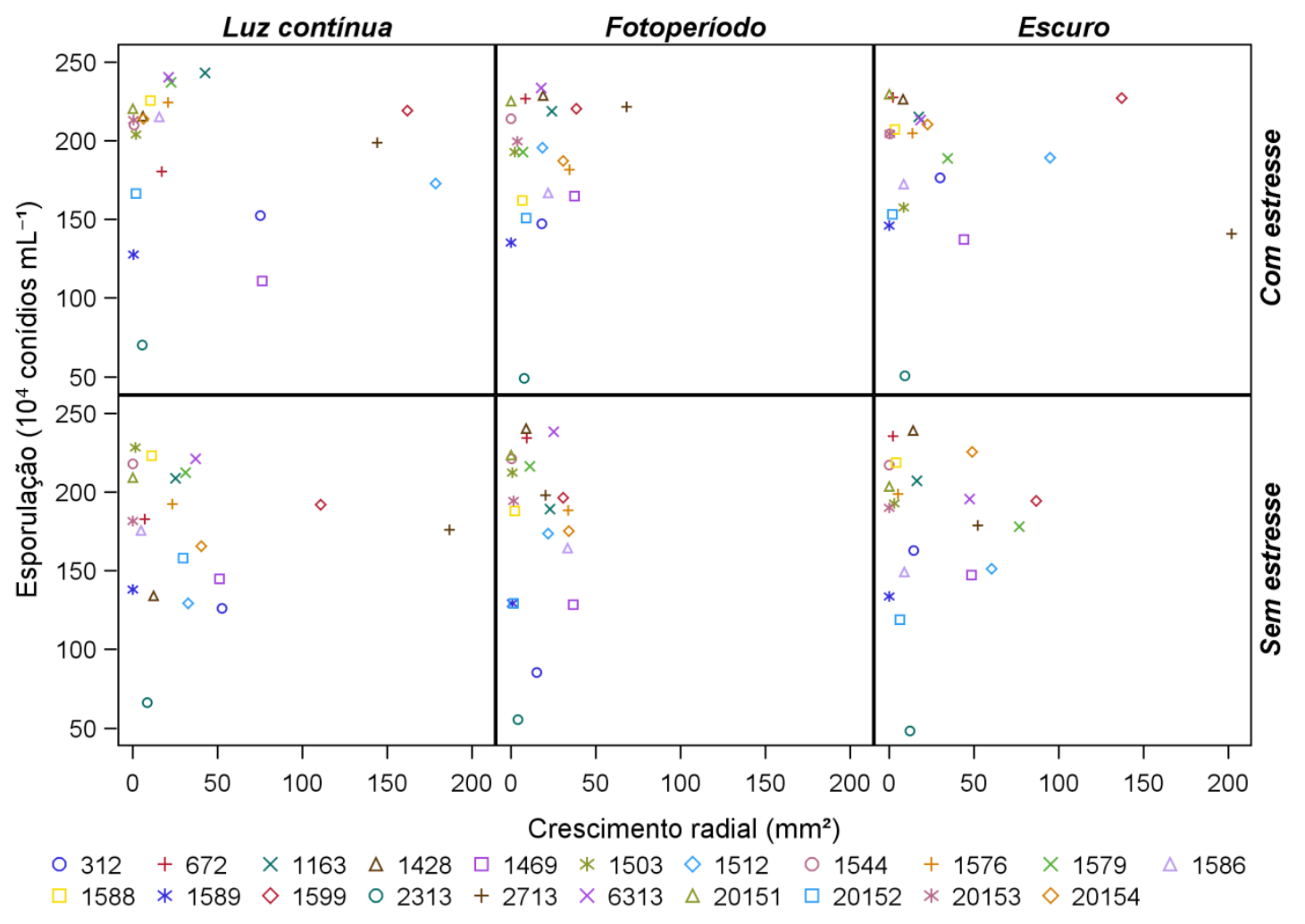

Figura 3. Gráfico de dispersão entre número de conídios $\left(10^{4}\right.$ conídios $\left.\mathrm{mL}^{-1}\right)$ e crescimento radial $\left(\mathrm{mm}^{2}\right)$ em isolados de C. cassiicola submetidos a diferentes regimes de iluminação e estresse mecânico.

diferentes hospedeiros apresentavam maior produção de esporos em regime de luz contínua ou escuro contínuo.

A Tabela 2 mostra as produções médias de conídios por isolado, por regime de iluminação e por regime de estresse. A produção de conídios da maioria dos isolados pôde ser modificada significativamente, a depender do regime de iluminação e da condição de estresse (Tabela 2). Examinando o efeito da iluminação nos isolados submetidos ao estresse mecânico, se observou que 14 deles produziram quantidades significativamente maiores de conídios em função da iluminação: CMES 312 e CMES 1588 (luz contínua); CMES 672 e CMES 1579 (luz contínua e fotoperíodo $12 \mathrm{~h} / 12 \mathrm{~h}$ ); CMES 1428, CMES 20152 e CMES 20153 (fotoperíodo 12 h/ 12 h); CMES 1512, CMES 1544, CMES 1579, CMES 1599 e CMES 2713 (luz contínua e escuro contínuo); CMES 20154 (fotoperíodo $12 \mathrm{~h} / 12$ h e escuro contínuo) e CMES 1503 (escuro contínuo). No entanto, para três isolados, o efeito da iluminação foi significativo apenas na condição sem estresse: CMES 1586 e CMES 1589 (fotoperíodo 12 h/ 12 h) e CMES 2313 (escuro contínuo).

Escolhendo-se um regime de iluminação, a aplicação do estresse mecânico produziu efeito significativo na produção de conídios de 12, dentre os 21 isolados estudados. Dentro do regime de luz contínua, a aplicação do estresse aos isolados CMES 1512, CMES 1544, CMES 1586 e 20153 aumentou significativamente suas produções de conídios, enquanto reduziu a produção de conídios do isolado 20154. No regime de fotoperíodo $12 \mathrm{~h} / 12 \mathrm{~h}$, os isolados que se beneficiaram da aplicação do estresse para aumentar a produção de conídios foram CMES 1503, CMES 1588, CMES 2713, 20152 e 20153, enquanto os isolados CMES 1544 e CMES 1589 reduziram significativamente as produções de conídios em função da aplicação do estresse mecânico. Finalmente, na condição de escuro, dentre os cinco isolados que alteraram significativamente suas produções de esporo em função da aplicação do estresse mecânico, três produziram significativamente maior quantidade de conídios (CMES 1503, CMES 1576 e CMES 2713) e dois reduziram a produção de conídios (CMES 6313 e 20152).

Com isso, pôde-se verificar que o fator determinante para a produção de esporos foi o isolado, tendo sido o estresse mecânico e a iluminação fatores que alteraram significativamente a esporulação. Contudo, o efeito desses fatores não se generalizou a todos os isolados avaliados. Esta variação no comportamento entre os diferentes isolados pode ser explicada pela alta diversidade genética da espécie de C. cassiicola (5).

Analisando as associações entre o crescimento micelial radial e as quantidades de esporos na Figura 3, em cada regime de iluminação e de estresse, observa-se que os isolados que apresentaram os maiores crescimentos miceliais radiais não necessariamente produziram as maiores quantidades de esporos. A ausência de associação linear naquela figura é corroborada pelo baixo valor do coeficiente de correlação de Pearson (-0,0042). Em particular, o isolado CMES 2313 que apresentou os menores valores de crescimento micelial radial e de esporulação não foi influenciado significativamente pelo regime de iluminação e de estresse (Figura 3).

Assim, pode-se afirmar que a esporulação e o crescimento micelial radial de isolados de $C$. cassiicola cultivados em diferentes regimes de luz e de estresse apresentam padrões específicos para cada isolado. O maior crescimento micelial não determina maior esporulação dos isolados fúngicos. A resposta dos isolados aos fatores analisados foram independentes das regiões geográficas de isolamento. No entanto, se a sensibilidade de um novo isolado às condições de iluminação e estresse for desconhecida, os resultados desse estudo mostram que o aumento da esporulação é mais provável com a incubação sob luz contínua ou escuro contínuo e aplicação de estresse mecânico. 


\section{REFERÊNCIAS}

1. Almeida, A. M. R., Ferreira, L. P., Yorinori, J. T., Silva, J. F. V., Henning, A. A., Godoy C. V., Costamilan L. M., Meyer M. C. Doenças da soja. In: Kimati H, Amorim L, Rezende J. A. M, Bergamin Filho A., Camargo L. E. A (Eds.). Manual de Fitopatologia - Vol. 2. Doenças de Plantas Cultivadas. 4. ed. São Paulo SP. Editora Agronômica Ceres. p. 570-588. 2005.

2. Almeida, A. M. R.; Yamashita, J. Crescimento e esporulação de Corynespora cassiicola (Berk. \& Curt.) Wei em diferentes meios de cultura. Fitopatologia Brasileira, Brasília, v.1, p. 203 -206, 1976.

3. Beckman, P. M.; Payne, G. A. Cultural techniques and conditions influencing growth and sporulation of Cercospora zeae-maydis and lesion development in corn. Phytopathology, Saint Paul, Minnesota, v.73 p. 286-289, 1983.

4. Companhia Nacional de Abastecimento (Conab). Acompanhamento da safra brasileira de grãos, v. 4 Safra 2016/17 - Segundo levantamento, Brasília, p. 1-156 novembro 2016.

5. Dixon, L. J., Schlub, R. L., Pernezny, K., and Datnoff, L. E. Host specializai tion and phylogenetic diversity of Corynespora cassiicola. Phytopathology, Saint Paul, Minnesota, v.99 p. 1015-1027, 2009.

6. Ellis, M. B. Dematiaceous hyphomycetes. Commonwealth Mycological Institute, Kew, Surrey, United Kingdom, p. 608, 1971.
7. Farr D. F.; Rossman A. Y. Fungal Databases, Systematic Mycology and Microbiology Laboratory, Agricultural Research Service, United States Department of Agriculture. 2013. Disponível em: http://nt.ars grin.gov/ fungaldatabases/ Acesso em: 01/11/2016.

8. Godoy, C. V.; Almeida, A. M. R.; Costamilan, L. M.; Meyer, M. C.; Dias, W. P.; Seixas, C. D. S.; Soares, R. M.; Henning, A. A., Yorinori, J. T.; Ferreira, L. P.; Silva, J. F. V. Doenças da soja. In: Kimati H, Amorim L, Rezende J. A. M., Bergamin Filho A., Camargo L. E. A. (Eds.). Manual de Fitopatologia - Vol. 2. Doenças de Plantas Cultivadas. 5. ed. Ouro Fino MG. Editora Agronômica Ceres. p. 657-675. 2016.

9. Hartman, G. L.; Sinclair, J. B.; Rupe, J. C. Compendium of soybean diseases. American Phytopathological Society Press, 4. ed., St. Paul, Minnesota p.27, 1999.

10. Onesiran, P.; Arny, D.; Durbin, R. D. Increasing sporulation of Corynespora cassiicola. Mycophathologia, New York, v. 55, p. 121-123, 1975

11. Teramoto A.; Parisi, M. C. M.; Cunha, M.G. Caracterização fisiológica de isolados de Corynespora cassiicola. Tropical Plant Pathology, Viçosa, MG, v. 38, p. 313-322, 2013.

12. Trione, E. J.; Leach, C. M. Light-induced sporulation and sporogenic substances in fungi. Phytopathology, St. Paul, Minnesota, v. 59, p. 1077 1083, 1969. 